\title{
Therapeutic approaches to pediatric COVID-19: an online survey of pediatric rheumatologists
}

\author{
Ales Janda ${ }^{1}$ (D) Catharina Schuetz ${ }^{2} \cdot$ Scott Canna ${ }^{3} \cdot$ Mark Gorelik $^{4} \cdot$ Maximilian Heeg $^{5} \cdot$ Kirsten Minden $^{6}$. \\ Claas Hinze $^{7} \cdot$ Ansgar Schulz $^{1} \cdot$ Klaus-Michael Debatin $^{1} \cdot$ Christian M. Hedrich $^{8} \cdot$ Fabian Speth $^{9}$
}

Received: 26 November 2020 / Accepted: 25 February 2021 / Published online: 8 March 2021

(c) The Author(s) 2021

\begin{abstract}
Data on therapy of COVID-19 in immunocompetent and immunosuppressed children are scarce. We aimed to explore management strategies of pediatric rheumatologists. All subscribers to international Pediatric Rheumatology Bulletin Board were invited to take part in an online survey on therapeutic approaches to COVID-19 in healthy children and children with autoimmune/inflammatory diseases (AID). Off-label therapies would be considered by $90.3 \%$ of the 93 participating respondents. In stable patients with COVID-19 on oxygen supply (stage I), use of remdesivir (48.3\%), azithromycin (26.6\%), oral corticosteroids (25.4\%) and/or hydroxychloroquine (21.9\%) would be recommended. In case of early signs of "cytokine storm" (stage II) or in critically ill patients (stage III) (a) anakinra (79.5\% stage II; 83.6\% stage III) or tocilizumab (58.0\% and $87.0 \%$, respectively); (b) corticosteroids (oral $67.2 \%$ stage II, intravenously $81.7 \%$ stage III); (c) intravenous immunoglobulins (both stages 56.5\%); or (d) remdesivir (both stages 46.7\%) were considered. In AID, $>94.2 \%$ of the respondents would not support a preventive adaptation of the immunomodulating therapy. In case of mild COVID-19, more than 50\% of the respondents would continue pre-existing treatment with immunoglobulins (100\%), hydroxychloroquine (94.2\%), anakinra (79.2\%) or canakinumab (72.5\%), or tocilizumab (69.8\%). Long-term corticosteroids would be reduced by $26.9 \%$ ( $<=2 \mathrm{mg} / \mathrm{kg} / \mathrm{d}$ ) and $50.0 \%$ ( $>2 \mathrm{mg} / \mathrm{kg} /$ day), respectively, with only $5.8 \%$ of respondents voting to discontinue the therapy. Conversely, more than $75 \%$ of respondents would refrain from administering cyclophosphamide and anti-CD20-antibodies. As evidence on management of pediatric COVID-19 is incomplete, continuous and critical expert opinion and knowledge exchange is helpful.
\end{abstract}

Keywords COVID-19 · SARS-CoV-2 · Children · Pediatric rheumatology · Autoimmune disease · Inflammation · Treatment $\cdot$ Opinion poll

Ales Janda

ales.janda@uniklinik-ulm.de

1 Department of Pediatrics and Adolescent Medicine, Ulm University Medical Center, Eythstrasse 24, 89075 Ulm, Germany

2 Department of Pediatrics, Medizinische Fakultät Carl Gustav Carus, Technische Universität Dresden, Dresden, Germany

3 University of Pittsburgh, Pittsburgh, PA, USA

4 Department of Pediatrics, Division of Allergy, Immunology, and Rheumatology, Columbia University Irving Medical Center, New York Presbyterian Morgan Stanley Childrens Hospital of New York, New York, NY, USA

5 Institute for Immunodeficiency, Center for Chronic Immunodeficiency (CCI), Medical Center - University of Freiburg, Faculty of Medicine, University of Freiburg, Freiburg, Germany

6 Charité University Medicine Berlin, German Rheumatism Research Center Berlin, Berlin, Germany

7 University Hospital Munster, Munster, Germany

8 Department of Women's \& Children's Health, Institute of Life Course and Medical Sciences, University of Liverpool \& Department of Paediatric Rheumatology, Alder Hey Childrens NHS Foundation Trust Hospital, Liverpool, Great Britain

9 Department of Pediatric Rheumatology, Pediatric Bone Marrow Transplantation and Immunology Unit, Center for Obstetrics and Pediatrics, University Medical Center Hamburg-Eppendorf, Hamburg, Germany 


\begin{tabular}{|c|c|}
\hline \multicolumn{2}{|c|}{ Abbreviations } \\
\hline ACR & American College of Rheumatology \\
\hline ADE & Antibody dependent enhancement \\
\hline AID & Autoimmune/inflammatory disease \\
\hline COVID-19 & Corona virus disease 2019 \\
\hline FDA & Food and Drug Administration \\
\hline HCQ & Hydroxychloroquine \\
\hline IVIG & Intravenous immunoglobulins \\
\hline JAK & Janus kinase \\
\hline MERS & $\begin{array}{l}\text { Middle east respiratory syndrome } \\
\text { coronavirus }\end{array}$ \\
\hline SARS & $\begin{array}{l}\text { Severe acute respiratory syndrome } \\
\text { coronavirus }\end{array}$ \\
\hline
\end{tabular}

\section{Introduction}

The newly emerged coronavirus SARS-CoV-2 (severe acute respiratory syndrome coronavirus 2 ) is the infectious pathogen causing COVID-19 (corona virus disease 2019), a pandemic that poses a threat to millions of lives and, therefore, a challenge to healthcare providers of all medical specialities. It became apparent that the shared expertise of rheumatologists and clinical immunologists is critical in the treatment of COVID-19 patients, as a significant proportion of adult and few pediatric patients develop hyperinflammatory disease [1-7].

While the course of COVID-19 in healthy children is usually asymptomatic or mild when compared to adults $[8$, 9], a hyperinflammation syndrome (pediatric inflammatory multisystem syndrome: PIMS or MIS-C: multisystem inflammatory syndrome in children) timely associated with SARS-CoV-2 has been described in a subset of pediatric patients in Europe and North America [2, 10-13]. Although patients with pediatric autoimmune/inflammatory disease (AID) may be more susceptible to virus infections when compared to age-matched healthy cohorts, and AID patientsreceiving immunomodulatory or immunosuppressive therapy are considered to be more susceptible towards viral and bacterial infections $[14,15]$, there is no reliable evidence to suggest a higher risk of SARS-CoV-2 infection or more severe disease in those patients [4, 16-21]. Whether immune deficiency and/or immunomodulating treatment may even prevent severe complications such as PIMS-TS/MIS-C remains unclear [22]. Thus, in the absence of prospective studies in large cohorts, management of patients-receiving immunosuppression/modulation remains a particular challenge, as data are preliminary and somewhat conflicting as to whether or which type of immunomodulation represents a risk or protective factor for developing hyperinflammatory complications [1, 3, 4, 23, 24]. Published COVID-19-related recommendations providing clinical guidance for the management of children and adolescents [25-31] are largely based on case series, retrospective cohort studies, pathophysiological considerations, or are derived from data on adult populations. As low-quality evidence and expert opinion prevail, continuous inter-collegial discussion facilitate clinical decision making.

Here, we present results of an online opinion poll among international pediatric rheumatologists on: (a) possible general therapy concepts in COVID-19 in children and adolescents and (b) clinical management of pediatric patients with AID-receiving immunomodulation treatment in the context of SARS-CoV-2 pandemic.

\section{Methods}

The survey collecting opinions within the international pediatric rheumatology community was conducted in line with the published recommendations for survey-based research [32].

Pediatric rheumatology professionals (1849 unique email addresses), subscribers to the international online Pediatric Rheumatology Bulletin Board administered at McMaster University in Canada (https://mailman.mcmaster.ca/mailm an/listinfo/ped-rhe-list), were invited to participate in the survey via an email distribution list. The survey form was put online using SurveyMonkey ® (https://www.surve ymonkey.com) and was open for response from May 28 to June 11, 2020. The participation was voluntary, no incentives were used. One reminder email was distributed. The exact wording of the online survey form is available at Supplementary Figure S1.

Data on respondents' institutions, their experience in pediatric rheumatology (in years) and their practical experience with the care of COVID-19 patients were collected. Respondents could express their readiness to consider use of (off-label) therapies in COVID-19-affected cases. A list of suggested drugs (see Fig. 1) was provided in alphabetical order. Potential treatment choices were available for inpatients stratified by COVID-19 disease severity:

(i) Stage I: pneumonia with oxygen demand; (ii) Stage II: additional respiratory deterioration and/or imminent cytokine storm; (iii) Stage III: a critically ill patient with acute respiratory distress syndrome or multiorgan failure.

Respondents could express their disapproval with the use of a particular drug at any stage of the disease ("I would not recommend this drug"). In case of uncertainty, a statement "I do not know" could be selected. In case of treating a patient with an increased risk of severe viral disease (e.g. a patient with relevant immunodeficiency or severe cardiopulmonary, nephrological or neurodegenerative underlying disease), respondents were asked whether they would choose the following therapies earlier in the course of the disease: (a) antiviral drugs; 


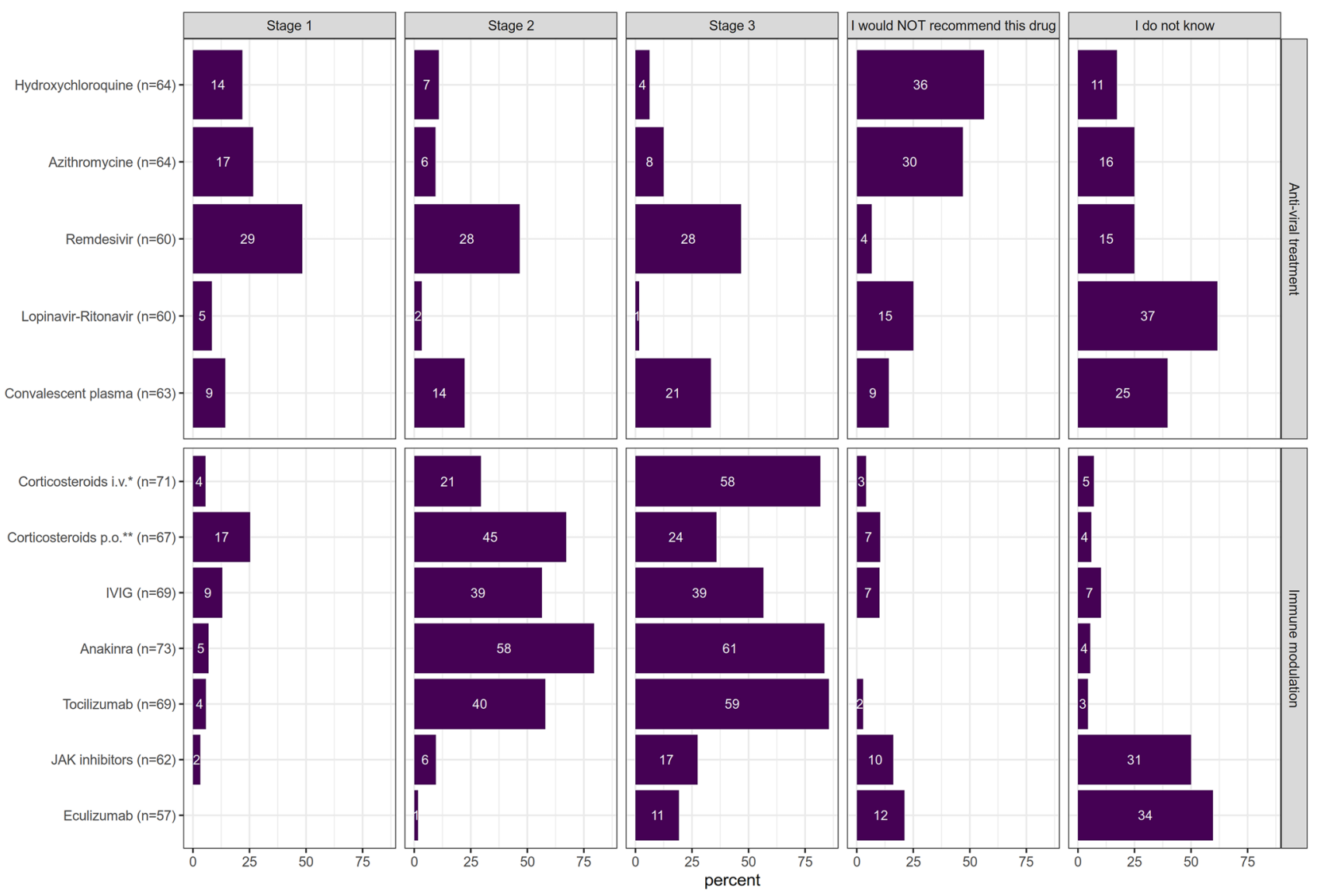

Fig. 1 Therapeutics considered for pediatric COVID-19. The number of respondents expressing their opinion on each treatment option is depicted in each line next to the drug name; number of respondents supporting the particular treatment is shown within the bars; their length reflects proportion of positive responses in case of the given

(b) corticosteroids; (c) immunomodulatory drugs; (d) cytokine blockade; (e) immunoglobulins; or (f) convalescent plasma.

Treatment options for PIMS/MIS-C were not specifically addressed in this survey.

In the second part of the survey, the approach to antiinflammatory, immunomodulatory/immunosuppressive therapy in patients with AID in the context of COVID-19 was addressed. First, respondents could report on their attitude towards preventive adaptation of the ongoing treatment for children with AID in the absence of SARS-CoV-2 exposure or infection. Second, respondents' treatment strategies in patients with mild symptoms of proven COVID-19 were addressed (list of the drugs in Fig. 2). Possible response options included "no change", "reducing" or "stop" the longterm medication.

Close-ended answer choices were applied in all questions. The online survey form was subjected to internal validation. Data anonymity were warranted. treatment. For better comprehension, the treatment options are split into two main categories (anti-viral and immunomodulatory therapy), though the therapeutic effects might be overlapping. *prednisolone $\leq 2 \mathrm{mg} / \mathrm{kg} / \mathrm{d}$, **high-dose prednisolone (10-30 mg/kg/d)

\section{Statistical analysis}

Only complete datasets (including respondents' characteristics, responses from part one and/or two) were subjects to analysis. Statistical analysis was performed using R (v 4.0.0) and the tidyverse packages dplyr (v 1.0.2). Graphics were generated using the $\mathrm{R}$ package ggplot2 (v 3.3.2). Doublesided Fisher's exact test was applied to compare frequencies of particular responses between different participant groups.

\section{Ethics statement}

The study was exempt from ethical review while no patients or study subjects were involved. Only anonymous demographic and expert opinion data were collected. The respondents were made aware in the text of the invitation email that the results of the survey will be eventually published. 


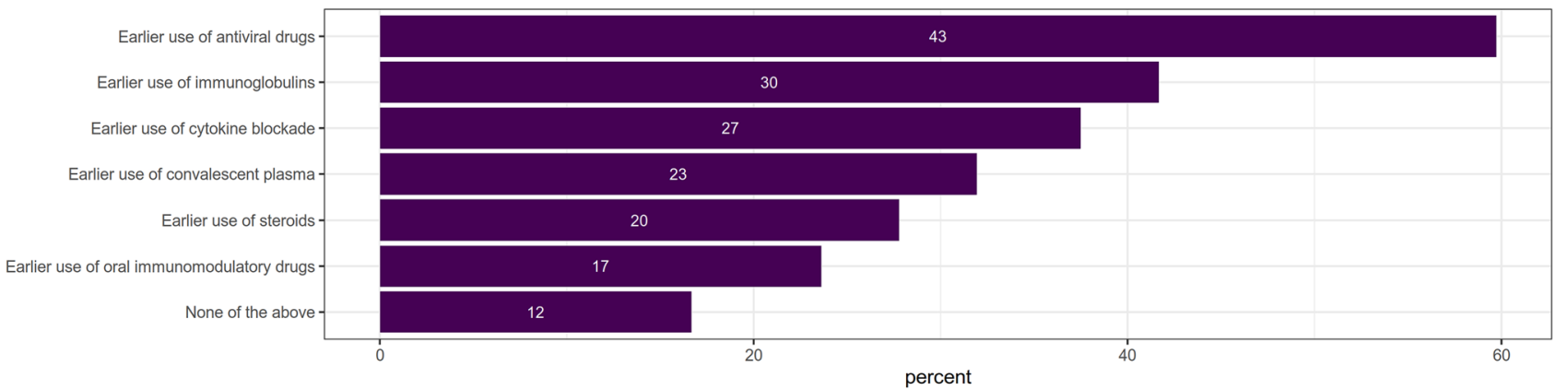

Fig. 2 Opinion on the possible earlier use of particular treatment modalities in course of COVID-19 in patients with increased risk for severe course of viral infections $(n=72$ respondents). Number of

Table 1 Respondents' characteristics

\begin{tabular}{lc}
\hline Type of medical setting $(n=93)$ & \\
\hline University hospital & $82(88.2 \%)$ \\
Other hospital & $10(10.8 \%)$ \\
Out-patient setting & $1(1.1 \%)$ \\
Geographical location $(n=90)$ & \\
Americas & $60(64.5 \%)$ \\
Europe & $24(25.8 \%)$ \\
Asia & $4(4.3 \%)$ \\
Africa & $1(1.1 \%)$ \\
Australia & $1(1.1 \%)$ \\
Experience in the field of pediatric rheumatology $(n=92)$ & \\
$<5$ years & $12(13.0 \%)$ \\
$5-10$ years & $31(33.3 \%)$ \\
$>10$ years & $49(52.7 \%)$ \\
Experience with treatment of patients with COVID-19 $(n=92)$ \\
Yes & $58(63.0 \%)$ \\
$1-5$ patients & $33(35.5 \%)$ \\
$>5$ patients & $25(26.9 \%)$ \\
Pediatric patients & $47(50.5 \%)$ \\
Adult patients & $2(2.2 \%)$ \\
All age categories & $8(8.7 \%)$ \\
No & $34(36.6 \%)$ \\
\end{tabular}

\section{Results}

\section{Respondents' characteristics}

Ninety-three members of the mailing list from 23 countries responded (5\% of all contacted individual email accounts) (Table 1). The majority of respondents worked in the U.S.A (50.5\%; Supplementary Table 1, Supplementary Figure S2), most of them at university hospitals $(88.2 \%)$. Over half of the respondents were senior healthcare professionals working in the field of pediatric rheumatology for over 10 years respondents supporting the given approach is shown at each bar; its length reflects proportion of positive responses

(52.7\%). About two-thirds indicated personal experience with the care of patients with COVID-19.

\section{Treatment strategies in pediatric patients with COVID-19}

Eighty-four respondents $(90.3 \%)$ would consider off-label treatment in COVID-19 (Fig. 1).

The first three most commonly suggested therapeutics for patients in stage I of COVID-19 were the ribonucleotide analogue remdesivir $(48.3 \%)$, the macrolide antibiotic azithromycin (26.6\%) and the antimalarial agent hydroxychloroquine (HCQ; 21.9\%). While HCQ and azithromycin lost support in the stage II (10.9\% for HCQ and $9.4 \%$ for azithromycin) as well as stage III (6.3\% and $12.5 \%)$, the use of remdesivir was considered beneficial by a similar proportion of respondents (46.7\% for both, stage II and III). Only relatively few respondents $(6.7 \%)$ would not recommend remdesivir at all. Indecisiveness with respect to the above-mentioned drugs was comparable (17.2\% in case of HCQ, $25 \%$ azithromycin, and $25 \%$ for remdesivir). Notably, a majority of respondents would use neither HCQ $(56.3 \%)$ nor azithromycin $(48.4 \%)$ at all. Use of lopinavir-ritonavir would be considered by only few respondents $(8.3 \%$; $3.3 \%$ and $1.7 \%$ for the three disease stages, respectively); the majority were undecided $(61.7 \%)$ or argued against its use (26.7\%). Administration of convalescent plasma gained importance for the respondents throughout the disease progression $(14.3 \% ; 22.2 \%$ and $35.0 \%)$. However, a relatively high proportion of respondents were undecided (40\%); only a small minority (14.3\%) expressed concern and would not administer convalescent plasma at all.

A significant proportion of respondents would consider immunomodulatory therapy in the management of pediatric COVID-19. Oral corticosteroid therapy (prednisolone $\leq 2 \mathrm{mg} / \mathrm{kg} / \mathrm{d}$ ) was the most frequently chosen option $(25.4 \%)$ in stage I. Its importance to the respondents increased with disease progression (stage II, 67.2\%). 
However, in case of severe disease with cytokine storm and multiorgan failure (stage III) high-dose intravenous corticosteroid therapy (prednisolone $10-30 \mathrm{mg} / \mathrm{kg} / \mathrm{d}$ ) would be preferred (81.7\% for the intravenous form versus $35.8 \%$ for the oral variant). More than half of the respondents considered administering intravenous immunoglobulins (IVIG) for more advanced disease (56.5\% for both stages II and III). A majority of respondents opted for cytokine blocking strategies in imminent or already active hyperinflammation as most important therapeutical approach. Blockade of IL-6 (tocilizumab, $85.5 \%$ ) or IL-1 (anakinra 83.6\%) in stage III was supported by most respondents. Interestingly, in milder disease (stage II), IL-1 blockade was considered more frequently (79.5\%) as compared to IL-6 blockade (58.8\%). None of the respondents argued against IL-1-blockade; similarly, opposition to IL-6 blockade with tocilizumab was low (3.0\%). Janus kinase (JAK) or complement (eculizumab) inhibition attracted the least attention as therapeutic strategy across disease stages, with highest support in stage III (27.4\% for JAK-inhibitors and $19.3 \%$ for eculizumab). With the exception of JAK and complement inhibition, most respondents expressed confidence in the efficacy of immunomodulatory therapy while the uncertainty fluctuated between 4.3 and $10.1 \%$. For the use of JAK (50\%) and complement inhibition (59.6\%), however, a majority of respondents were undecided.

Next, we asked whether treatment decisions and choice of particular drugs would depend on the respondents' experience and/or characteristics. The only significant difference was found for the use of HCQ $(p=0.025)$ and azithromycin $(p=0.026)$. More senior colleagues $(>10$ years of experience) would use HCQ and azithromycin more readily (in stage I) and were generally less critical of these options.

\section{Treatment approaches in potentially immunocompromised patients}

When comparing responses concerning treatment of patients with increased risk for viral infections with those of otherwise healthy COVID-19 patients (Fig. 2), our respondents would promote an earlier use of antiviral drugs $(59.7 \%$ of the respondents), followed by use of immunoglobulins (41.7\%), cytokine blockade (37.5\%), convalescent plasma (31.9\%), corticosteroids (27.8\%) and oral immunomodulatory drugs (23.6\%) in the course of the disease. Twelve respondents would choose neither of those options.

The choice differences between the participants' groups were not statistically significant.

\section{Approach to pre-existing anti-inflammatory, immunomodulatory and immunosuppressive therapy in patients with AID in the context of COVID-19 pandemic}

Fifty-eight respondents (62.4\%) submitted their responses for this section of the survey. For patients without SARSCoV-2 infection or signs of COVID-19, 94.2\% of those respondents would continue established anti-inflammatory/ immunomodulating therapy. Three respondents would consider reduction or discontinuation of an existing long-term therapy in patients with clinically inactive rheumatological disease.

In AID patients with proven "mild" (stage I) COVID-19 (Fig. 3) the following therapies would be continued: immunoglobulin therapy (100\%), HCQ (94.2\%), IL-1 blockade with canakinumab and anakinra $(72.5 \%$ and $79.2 \%$, respectively) and IL-6 blockade (with support of $69.8 \%$ respondents). The majority of the respondents would discontinue or modify (postpone or reduce a dose) therapies with mTORinhibitors (80\%), CTLA-4-blockade (76.5\%), mycophenolate mofetil (75.5\%), BAFF-blockade (75\%), IL-12/23-blockade (70.8\%), calcineurin inhibitors (69.2\%), JAK inhibition (68.7\%), TNF- $\alpha$ blockade (67.9\%), methotrexate (64.2\%), azathioprine (61.5\%) and leflunomide (59.6\%). Treatment with dapsone would be reduced by $46.5 \%$ of the respondents. Over $75 \%$ of respondents would refrain from initiating therapy with cyclophosphamide $(84.6 \%)$ or anti-CD20antibodies (74.9\%).

Discontinuation of long-term oral corticosteroid therapy ( $\leq 2$ as well as $>2 \mathrm{mg} / \mathrm{kg} / \mathrm{d}$ ) would only be considered by $5.8 \%$ of respondents. However, a majority of respondents would consider dose reduction $(26.9 \%$ in $\leq 2 \mathrm{mg} / \mathrm{kg} / \mathrm{d} ; 50 \%$ in $>2 \mathrm{mg} / \mathrm{kg} / \mathrm{d}$ ). As many as $27.5 \%$ would discontinue/ refrain from intravenous high-dose "pulse" therapy with methylprednisolone, $41.2 \%$ would reduce the dose.

The only statistically significant difference between the groups of respondents was found in case of IL-6 blockade with tocilizumab. The majority of senior colleagues ( $>10$ years of experience in pediatric rheumatology) would recommend maintenance of the IL-6 blockade (83.9\%) in comparison to the less experienced colleagues who would endorse this approach in only 50\% $(p=0.014)$.

\section{Discussion}

An opinion data of almost one hundred international pediatric rheumatologists at the time of peaking COVID19 pandemic are presented. Due to the rapid evidence evolvement in these unique times may this survey impose slightly outdated. However, the growing body of evidence regarding treatment options in patients with COVID-19 


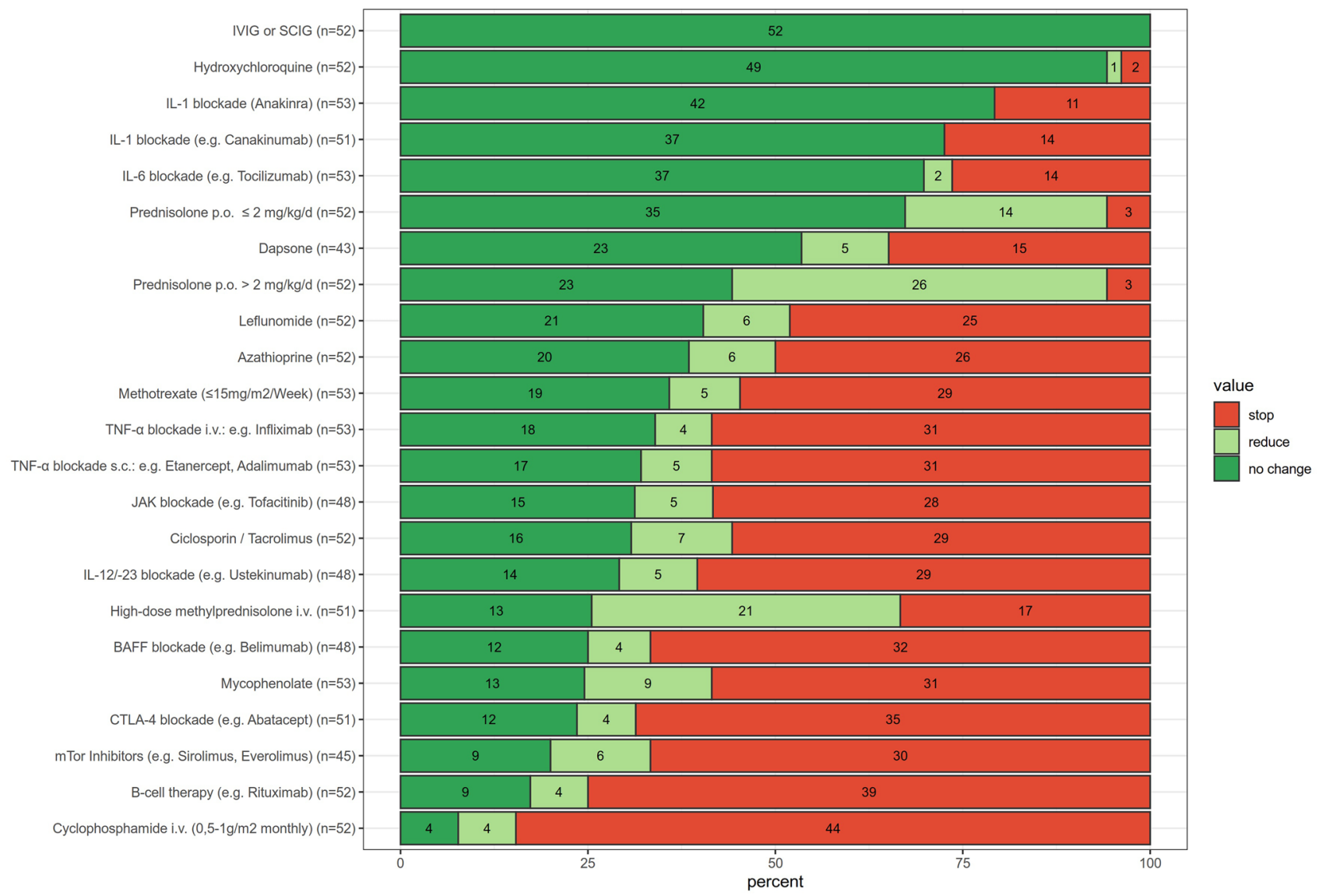

Fig. 3 Opinion on how to approach established anti-inflammatory/ immunomodulatory treatment in patients with autoimmune/inflammatory disease (AID) and confirmed mild COVID-19 disease. The number of respondents expressing their opinion on each medication is depicted next to the graph; the number of respondents supporting a

or management strategies of individuals with AID applies still mainly to the adult population. Furthermore, the care for children and adolescent with COVID-19 as well as the approach to the pediatric patients with AID in context of the COVID-19 pandemic remains controversial and only scarce data on changes in health care of pediatric patients with rheumatic diseases are available [33, 34].

\section{Treatment strategies in pediatric patients with COVID-19}

In this survey, remdesivir was the most frequently considered virus-directed drug in pediatric patients (almost 50\% support throughout all disease stages). Frequent concurrent choice of remdesivir and/or cytokine blockade and/or corticosteroid therapy points towards possible combination strategies. This opinion is very well in line with later published data on positive clinical effects in a subset of patients with COVID-19 [35-37]. Those findings resulted in an particular approach is shown for each bar; its length reflects the proportion of positive responses. The treatment options are arranged in descending order with respect to how strongly physicians felt about continuing treatment despite mild COVID-19

emergency use authorization from the US Food and Drugs Administration (FDA), including children over 12 years of age and/or weighing more than $40 \mathrm{~kg}$ [38], followed by approval in Europe [39]. Early use during the viral replication stage seems to be most beneficial [40, 41].

Within the group of immunomodulatory drugs corticosteroid use gained the highest respondents' support, reaching $35.8 \%$ and $81.7 \%$ use of oral and intravenous corticosteroids, respectively, for patients in stage III. This view corresponds with "real life" COVID-19 treatment data worldwide [42] and is underpinned by the findings from the RECOVERY study on use of dexamethasone [43]. However, a precaution is warranted as the application of dexamethasone in this trial improved outcome only in those on respiratory support [43].

Cytokine blocking strategy (blockade of IL-1 and IL-6) was the most often chosen treatment option for patients with clinically severe COVID-19 reaching support of $83.6 \%$ and $85.5 \%$ respondents, respectively, for use in stage III. This is in line with data from case series and individual case reports 
$[2,44,45]$, at times in combination with high-dose methylprednisolone [46]. The popularity of anakinra may be based on its great potential to control hyperinflammation, but also its excellent safety profile including use in patients with bacterial sepsis and cytokine storm [47]. In addition, anakinra as well as tocilizumab are approved for use in cytokine release syndrome (macrophage activation syndrome) from 8 and 24 months of age, respectively.

The most controversial findings in the survey concern HCQ and azithromycin. Results of a small clinical trial at the onset of the pandemic showed enhancement of the clearance effect on SARS-CoV-2 by addition of azithromycin to HCQ therapy [48]. This controversial study contributed to optimism and broad uncritical endorsement of HCQ and azithromycin in treating COVID-19. However, growing evidence from controlled clinical trials [49-52] did not show conclusive benefit of the therapy. Moreover, cardiotoxicity, namely rhythm disorders, became an increased concern among adult patients [53, 54]. Currently, HCQ and/or azithromycin are not recommended for treatment of COVID-19. Participants of this survey were rather hesitant about using HCQ and/or azithromycin in COVID-19; however, still around a quarter of them would consider their use in the stage I. The dynamics of opinion change and growing skepticism towards these treatment modalities could be demonstrated when compared to a related, but previous survey that we performed among German-speaking pediatric rheumatologists [55].

Recently, it has been shown that the immunocompromised state of patients with primary immunodeficiency is not a predominant factor for severe course of COVID-19 [22]. With exception of deficiency in type I interferon signaling $[22,56]$ or presence of autoantibodies against interferons [57]. Secondary immunodeficiency due to chemotherapy in pediatric patients treated for malignant disease is associated with longer viral clearance; however, with only minimally increased risk of severe course of COVID-19 [58]. Thus, the current available data do not justify therapy intensification against SARS-CoV-2 infection in all immunocompromised children considered by some of our respondents and support individualized approach.

\section{Approach to pre-existing anti-inflammatory, immunomodulatory and immunosuppressive therapy in patients with AID in the context of COVID-19 pandemic}

Support for the continuation of pre-existing immunomodulatory and/or immunosuppressive therapy in patients with AID without proven COVID-19 documented in the survey is in line with recommendations of the American College of Rheumatology (ACR) [30] as well as the European societies $[31,59]$ published after closure of this survey.
In the case of an incipient COVID-19 disease, almost all respondents were in favor of continuing ongoing therapy with HCQ and subcutaneous or intravenous immunoglobulins for the underlying rheumatological disease. In fact, there is no evidence for a disadvantage of these drugs in the context of COVID-19 [60]. The majority of colleagues would also continue a pre-existing oral steroid therapy, however, reduce higher dosages beyond $2 \mathrm{mg} / \mathrm{kg} / \mathrm{d}$. The ACR recommends continuation of long-term steroid therapy taking into account the risk of potential adrenal cortex insufficiency (with a pre-treatment period of $>14$ days) [30]. The majority of respondents argued against immediate termination of IL-1 or IL-6 inhibition. Discontinuation of a short-acting IL-1-targeted therapy such as anakinra, carries the risk of a rebound phenomenon of the underlying (systemic) rheumatic or inflammatory diseases. Moreover, it may trigger a macrophage activation syndrome, a complication was also observed in some COVID-19 patients [61]. Data supporting continuation of IL-1-blockade during mild COVID-19 has been recently published: a mild course of the infection was shown in three children and one adult treated for autoinflammatory disease with IL-1-targeted therapy [62]. After recovery from the infection two out of the three pediatric patients suffered from an increased autoinflammatory activity. Those flares were presumably due to the underlying disease and not related to the IL-1-targeted therapy [62].

A large number of respondents favors a continuation of dapsone, mycophenolate, leflunomide, methotrexate, azathioprine and calcineurin-inhibitors, possibly administered in reduced dosages. Presumably, antiproliferative drugs would be continued for fear of a severe relapse, e.g. in connective tissue diseases and vasculitides. In COVID-19 patientsreceiving ongoing immunomodulating/suppressive drugs, close monitoring of blood count changes, liver and kidney toxicity and, parameters such as IgG, IgM and CD4 T-cell numbers are justified [63].

The majority of respondents would pause TNF-alpha inhibitors and IL-12/23-inhibitors in COVID-19 patients. As in other virus infections, this is a standard approach for patients with inactive juvenile (psoriatic) arthritis due to the fast effect at restart of TNF-alpha inhibitors post-infection. Moderate-to-highly immunosuppressive agents with long half-lives such as cyclophosphamide, anti-CD20 and antiBAFF antibodies, CTLA-4 IgG would be omitted or discontinued [1].

The data published after closure of the survey do not show substantially increased risk of infection or severe course of COVID-19 in AID patients-receiving immunosuppressive and/or biologic treatment [64-66]. A possibly less stringent approach regarding the long-term immunomodulatory therapy than suggested from our respondents might be required. 


\section{Limitations}

The results of this survey depict personal therapeutic decision-making perspectives amid COVID-19 pandemics. The heterogeneity of the clinical scenarios and possible (combination) therapies were not explicitly addressed. Some of the respondents had no or limited experience in treating COVID-19 patients so that the statements are partially based on hypothetical considerations. The results are based on participation of relatively large group of specialists; however, a non-response bias has to be taken into account as majority of the addressed experts did not respond. Similarly, the unequal distribution of geographical origin of the respondents may affect the overall result. Thus, our conclusions are preliminary and not meant as treatment recommendations.

\section{Conclusions}

There is a growing evidence that pediatric patients with AID receiving immunomodulatory therapy are not substantially endangered by SARS-CoV-2 beyond the common risk of viral infections. Responses from this survey are largely in line with the evolving findings and endorse continuation of most of the immunomodulatory therapies in case of mild COVID-19. While a severe or complicated course of acute COVID-19 in pediatric population remains rare, the hyperinflammatory state (PIMS-TS/MISC) constitutes a significant clinical challenge and requires continuous attention and further research.

Supplementary Information The online version contains supplementary material available at https://doi.org/10.1007/s00296-021-04824-4.

Acknowledgements We would like to thank Jana Hörstermann for her help in preparing the online survey in SurveyMonkey ${ }^{\circledR}$ and all respondents for sharing their opinions.

Authors' contributions AJ, CS, CMH, FS designed the study, drafted the survey, analyzed the data and wrote the manuscript. MG contributed to the design of the study, performed the statistical analysis of the collected data, produced the figures and reviewed the manuscript. SC, $\mathrm{MH}, \mathrm{KM}, \mathrm{KMD}, \mathrm{CH}$, AS contributed to the survey design, validated the survey form and reviewed the manuscript. All authors revised the manuscript, approved its final version and agree to be accountable for all aspects of the work.

Funding Open Access funding enabled and organized by Projekt DEAL. No specific funding for this study was applied.

\section{Declarations}

Conflict of interest The authors declare that the research was conducted in the absence of any commercial or financial relationships that could be seen as a potential conflict of interest.
Ethics approval The study was exempt from ethical review while no patients or study subjects were involved. Only anonymous demographic and expert opinion data were collected.

Consent for publication The respondents were made aware in the text of the invitation email that the results of the survey will be eventually published.

Open Access This article is licensed under a Creative Commons Attribution 4.0 International License, which permits use, sharing, adaptation, distribution and reproduction in any medium or format, as long as you give appropriate credit to the original author(s) and the source, provide a link to the Creative Commons licence, and indicate if changes were made. The images or other third party material in this article are included in the article's Creative Commons licence, unless indicated otherwise in a credit line to the material. If material is not included in the article's Creative Commons licence and your intended use is not permitted by statutory regulation or exceeds the permitted use, you will need to obtain permission directly from the copyright holder. To view a copy of this licence, visit http://creativecommons.org/licenses/by/4.0/.

\section{References}

1. Felsenstein S, Herbert JA, McNamara PS, Hedrich CM (2020) COVID-19: Immunology and treatment options. Clin Immunol 215:108448. https://doi.org/10.1016/j.clim.2020.108448

2. Pain CE, Felsenstein S, Cleary G et al (2020) Novel paediatric presentation of COVID-19 with ARDS and cytokine storm syndrome without respiratory symptoms. Lancet Rheumatol. https:// doi.org/10.1016/S2665-9913(20)30137-5

3. Felsenstein S, Hedrich CM (2020) SARS-CoV-2 infections in children and young people. Clin Immunol 220:108588. https:// doi.org/10.1016/j.clim.2020.108588

4. Hedrich CM (2020) COVID-19 - Considerations for the paediatric rheumatologist. Clin Immunol 214:108420. https://doi. org/10.1016/j.clim.2020.108420

5. Swann OV, Holden KA, Turtle L et al (2020) Clinical characteristics of children and young people admitted to hospital with covid-19 in United Kingdom: Prospective multicentre observational cohort study. BMJ 370:m3249. https://doi.org/10.1136/bmj. m3249

6. Knight SR, Ho A, Pius R et al (2020) Risk stratification of patients admitted to hospital with covid-19 using the ISARIC WHO Clinical Characterisation Protocol: Development and validation of the 4C Mortality Score. BMJ 370:m3339. https://doi.org/10.1136/ bmj.m3339

7. Docherty AB, Harrison EM, Green CA et al (2020) Features of 20133 UK patients in hospital with covid-19 using the ISARIC WHO Clinical Characterisation Protocol: prospective observational cohort study. BMJ 369:m1985. https://doi.org/10.1136/bmj. m1985

8. Ding Y, Yan H, Guo W (2020) Clinical Characteristics of Children With COVID-19: A Meta-Analysis. Front Pediatr 8:431. https:// doi.org/10.3389/fped.2020.00431

9. Castagnoli R, Votto M, Licari A et al (2020) Severe Acute respiratory syndrome coronavirus 2 (SARS-CoV-2) infection in children and adolescents: A systematic review. JAMA Pediatr 174:882889. https://doi.org/10.1001/jamapediatrics.2020.1467

10. Pouletty M, Borocco C, Ouldali N et al (2020) Paediatric multisystem inflammatory syndrome temporally associated with SARS-CoV-2 mimicking Kawasaki disease (Kawa-COVID-19): 
A multicentre cohort. Ann Rheum Dis 79:999-1006. https://doi. org/10.1136/annrheumdis-2020-217960

11. Verdoni L, Mazza A, Gervasoni A et al (2020) An outbreak of severe Kawasaki-like disease at the Italian epicentre of the SARSCoV-2 epidemic: an observational cohort study. Lancet 395:17711778. https://doi.org/10.1016/S0140-6736(20)31103-X

12. Belot A, Antona D, Renolleau S, et al (2020) SARS-CoV-2-related paediatric inflammatory multisystem syndrome, an epidemiological study, France, 1 March to 17 May 2020. Eurosurveillance 25:pii=2001010. https://doi.org/https://doi.org/10.2807/15607917.ES.2020.25.22.2001010

13. Diorio C, Henrickson SE, Vella LA et al (2020) Multisystem inflammatory syndrome in children and COVID-19 are distinct presentations of SARS-CoV-2. J Clin Invest 130:5967-5975. https://doi.org/10.1172/JCI140970

14. Speth F, Wellinghausen N, Haas JP (2013) Screening investigations during intensified immunosuppression in children and adolescents. Part 1. Z Rheumatol 72:814-821. https://doi. org/10.1007/s00393-013-1200-3

15. Speth F, Wellinghausen N, Haas JP (2013) Screening investigations during intensified immunosuppression in children and adolescents. Part 2. Z Rheumatol 72:896-909. https://doi. org/10.1007/s00393-013-1203-0

16. Gao Y, Chen Y, Liu M et al (2020) Impacts of immunosuppression and immunodeficiency on COVID-19: A systematic review and meta-analysis. J Infect 81:e93-e95. https://doi.org/10.1016/j. jinf.2020.05.017

17. Minotti C, Tirelli F, Barbieri E et al (2020) How is immunosuppressive status affecting children and adults in SARS-CoV-2 infection? A systematic review. J Infect 81:e61-e66. https://doi. org/10.1016/j.jinf.2020.04.026

18. Monti S, Balduzzi S, Delvino P et al (2020) Clinical course of COVID-19 in a series of patients with chronic arthritis treated with immunosuppressive targeted therapies. Ann Rheum Dis 79:667-668. https://doi.org/10.1136/annrheumdis-2020-217424

19. Filocamo G, Minoia F, Carbogno S, et al (2020) Absence of severe complications from SARS-CoV-2 infection in children with rheumatic diseases treated with biologic drugs. J Rheumatol Apr 25:jrheum.200483. https://doi.org/https://doi.org/10.3899/jrheu m. 200483

20. Michelena X, Borrell H, López-Corbeto $M$ et al (2020) Incidence of COVID-19 in a cohort of adult and paediatric patients with rheumatic diseases treated with targeted biologic and synthetic disease-modifying anti-rheumatic drugs. Semin Arthritis Rheum 50:564-570. https://doi.org/10.1016/j.semarthrit.2020.05.001

21. Marlais M, Wlodkowski T, Vivarelli M et al (2020) The severity of COVID-19 in children on immunosuppressive medication. Lancet Child Adolesc Heal 4:e17-e18. https://doi.org/10.1016/ S2352-4642(20)30145-0

22. Meyts I, Bucciol G, Quinti I et al (2020) Coronavirus disease 2019 in patients with inborn errors of immunity: An international study. J Allergy Clin Immunol. https://doi.org/10.1016/j. jaci.2020.09.010

23. Ferro F, Elefante E, Puxeddu I et al (2020) Editorial: COVID19: The new challenge for rheumatologists. First update Clin Exp Rheumatol 38:373-382

24. Campbell JI, Ocwieja KE, Nakamura MM (2020) A Call for Pediatric COVID-19 Clinical Trials. Pediatrics. https://doi. org/10.1542/peds.2020-1081

25. Chen ZM, Fu JF, Shu Q et al (2020) Diagnosis and treatment recommendations for pediatric respiratory infection caused by the 2019 novel coronavirus. World J Pediatr 16:240-246. https://doi. org/10.1007/s12519-020-00345-5

26. RCPCH Clinical Guidelines (2020) COVID-19 - guidance for paediatric services in management of COVID-19. Last modified on January 11, 2021. https://www.rcpch.ac.uk/resources/covid-19guidance-paediatric-services. Accessed 30 Jan 2021

27. Centers for Disease Control and Prevention (2020) COVID-19: Information for Pediatric Healthcare Providers. Last modified on December 30, 2020. https://www.cdc.gov/coronavirus/2019-ncov/ hcp/pediatric-hcp.html. Accessed 5 Feb 2021

28. American Academy of Pediatrics (2020) Critical Updates on COVID-19. https://services.aap.org/en/pages/2019-novel-coron avirus-covid-19-infections/. Accessed 5 Feb 2020

29. Calvo C, García López-Hortelano M, de Carlos Vicente JC et al (2020) Recommendations on the clinical management of the COVID-19 infection by the "new coronavirus" SARS-CoV2. Spanish Paediatric Association working group. An Pediatr 92:241. e1-241.e11. https://doi.org/10.1016/j.anpedi.2020.02.001

30. Wahezi DM, Lo MS, Rubinstein TB et al (2020) American College of Rheumatology Guidance for the Management of Children with Pediatric Rheumatic Disease During the COVID-19 Pandemic: Version 1. Arthritis Rheumatol Art. https://doi. org/10.1002/art.41455

31. Paediatric Rheumatology European Society (2020) Updated PRES recommendations for coronavirus outbreak. Updated on September 21, 2020. https://www.pres.eu/news/newsstory. html?id=29. Accessed 30 Jan 2021

32. Gaur PS, Zimba O, Agarwal V, Gupta L (2020) Reporting Survey Based Studies - a Primer for Authors. J Korean Med Sci 35:e398. https://doi.org/10.3346/jkms.2020.35.e398

33. Batu ED, Lamot L, Sag E et al (2020) How the COVID-19 pandemic has influenced pediatric rheumatology practice: Results of a global, cross-sectional, online survey. Semin Arthritis Rheum 50:1262-1268. https://doi.org/10.1016/j.semarthrit .2020.09.008

34. Batu ED, Özen S (2020) Implications of COVID-19 in pediatric rheumatology. Rheumatol Int 40:1193-1213. https://doi. org/10.1007/s00296-020-04612-6

35. Wang Y, Zhang D, Du G et al (2020) Remdesivir in adults with severe COVID-19: a randomised, double-blind, placebo-controlled, multicentre trial. Lancet 395:1569-1578. https://doi. org/10.1016/S0140-6736(20)31022-9

36. Goldman JD, Lye DCB, Hui DS et al (2020) Remdesivir for 5 or 10 days in patients with severe Covid-19. N Engl J Med 383:1827-1837. https://doi.org/10.1056/nejmoa2015301

37. Grein J, Ohmagari N, Shin D et al (2020) Compassionate Use of Remdesivir for Patients with Severe Covid-19. N Engl J Med 382:2327-2336. https://doi.org/10.1056/nejmoa2007016

38. U.S. Food and Drug Administration (2020) COVID-19 Update: FDA Broadens Emergency Use Authorization for Veklury (remdesivir) to Include All Hospitalized Patients for Treatment of COVID-19. Released on August 28, 2020. In: FDA News Release. https://www.fda.gov/news-events/press-announcements/covid-19update-fda-broadens-emergency-use-authorization-veklury-remde sivir-include-all-hospitalized. Accessed 5 Feb 2021

39. European Centre for Disease Prevention and Control (2020) Veklury (remdesivir). Date of issue marketing authorisation on July 3, 2020. https://www.ema.europa.eu/en/medicines/human/ EPAR/veklury. Accessed 5 Feb 2021

40. Sheahan TP, Sims AC, Leist SR et al (2020) Comparative therapeutic efficacy of remdesivir and combination lopinavir, ritonavir, and interferon beta against MERS-CoV. Nat Commun 11:222. https://doi.org/10.1038/s41467-019-13940-6

41. Siddiqi HK, Mehra MR (2020) COVID-19 illness in native and immunosuppressed states: A clinical-therapeutic staging proposal. J Hear Lung Transplant 39:405-407. https://doi. org/10.1016/j.healun.2020.03.012

42. Fajgenbaum DC, Khor JS, Gorzewski A et al (2020) Treatments Administered to the First 9152 Reported Cases of COVID-19: 
A Systematic Review. Infect Dis Ther 9:435-449. https://doi. org/10.1007/s40121-020-00303-8

43. The RECOVERY Collaborative Group (2020) Dexamethasone in Hospitalized Patients with Covid-19 - Preliminary Report. N Engl J Med July 17:NEJMoa2021436. https://doi.org/https://doi. org/10.1056/nejmoa2021436

44. Zhang X, Song K, Tong F et al (2020) First case of COVID-19 in a patient with multiple myeloma successfully treated with tocilizumab. Blood Adv 4:1307-1310. https://doi.org/10.1182/blood advances.2020001907

45. Alzghari SK, Acuña VS (2020) Supportive Treatment with Tocilizumab for COVID-19: A Systematic Review. J Clin Virol 127:104380. https://doi.org/10.1016/j.jcv.2020.104380

46. Ramiro S, Mostard RLM, Magro-Checa C et al (2020) Historically controlled comparison of glucocorticoids with or without tocilizumab versus supportive care only in patients with COVID19-associated cytokine storm syndrome: Results of the CHIC study. Ann Rheum Dis 79:1143-1151. https://doi.org/10.1136/ annrheumdis-2020-218479

47. Shakoory B, Carcillo JA, Chatham WW et al (2016) Interleukin-1 Receptor Blockade Is Associated with Reduced Mortality in Sepsis Patients with Features of Macrophage Activation Syndrome: Reanalysis of a Prior Phase III Trial*. Crit Care Med 44:275-281. https://doi.org/10.1097/CCM.0000000000001402

48. Gautret P, Lagier JC, Parola P et al (2020) Hydroxychloroquine and azithromycin as a treatment of COVID-19: results of an open-label non-randomized clinical trial. Int J Antimicrob Agents 56:105949. https://doi.org/10.1016/j.ijantimicag.2020.105949

49. Singh AK, Singh A, Singh R, Misra A (2020) Hydroxychloroquine in patients with COVID-19: A Systematic Review and metaanalysis. Diabetes Metab Syndr Clin Res Rev 14:589-596. https ://doi.org/10.1016/j.dsx.2020.05.017

50. Tang W, Cao Z, Han M et al (2020) Hydroxychloroquine in patients with mainly mild to moderate coronavirus disease 2019: Open label, randomised controlled trial. BMJ 369:m1849. https ://doi.org/10.1136/bmj.m1849

51. Furtado RHM, Berwanger O, Fonseca HA et al (2020) Azithromycin in addition to standard of care versus standard of care alone in the treatment of patients admitted to the hospital with severe COVID-19 in Brazil (COALITION II): a randomised clinical trial. Lancet 396:959-967. https://doi.org/10.1016/S0140 $-6736(20) 31862-6$

52. Juul S, Nielsen EE, Feinberg J et al (2020) Interventions for treatment of COVID-19: A living systematic review with meta-analyses and trial sequential analyses (The LIVING Project). PLOS Med 17:e1003293. https://doi.org/10.1371/journal.pmed.1003293

53. Romani S, Gérard A, Fresse A et al (2021) Insights on the Evidence of Cardiotoxicity of Hydroxychloroquine Prior and During COVID-19 Epidemic. Clin Transl Sci 14:163-169. https://doi. org/10.1111/cts. 12883

54. Nguyen LS, Dolladille C, Drici MD et al (2020) Cardiovascular toxicities associated with hydroxychloroquine and azithromycin: An analysis of the world health organization pharmacovigilance database. Circulation 142:303-305. https://doi.org/10.1161/ CIRCULATIONAHA.120.048238
55. Janda A, Schuetz C, Heeg M et al (2020) COVID-19: treatment strategies of German-speaking pediatric rheumatologists: Results of an online survey. Z Rheumatol 79:710-717. https:// doi.org/10.1007/s00393-020-00854-8

56. Zhang Q, Liu Z, Moncada-Velez M et al (2020) Inborn errors of type I IFN immunity in patients with life-threatening COVID-19. Science. https://doi.org/10.1126/science.abd4570

57. Bastard P, Rosen LB, Zhang Q et al (2020) Autoantibodies against type I IFNs in patients with life-threatening COVID-19. Science. https://doi.org/10.1126/science.abd4585

58. Bisogno G, Provenzi M, Zama D et al (2020) Clinical characteristics and outcome of severe acute respiratory syndrome coronavirus 2 infection in italian pediatric oncology patients: a study from the infectious diseases working group of the associazione Italiana di Oncologia e Ematologia Pediatrica. J Pediatric Infect Dis Soc 9:530-534. https://doi.org/10.1093/jpids/piaa088

59. Landewé RBM, Landewé RBM, MacHado PM et al (2020) EULAR provisional recommendations for the management of rheumatic and musculoskeletal diseases in the context of SARSCoV-2. Ann Rheum Dis 79:851-858. https://doi.org/10.1136/ annrheumdis-2020-217877

60. Konig MF, Kim AH, Scheetz MH et al (2020) Baseline use of hydroxychloroquine in systemic lupus erythematosus does not preclude SARS-CoV-2 infection and severe COVID-19. Ann Rheum Dis 79:1386-1388. https://doi.org/10.1136/annrheumdi s-2020-217690

61. Franzetti M, Pozzetti U, Carugati M et al (2020) Interleukin-1 receptor antagonist anakinra in association with remdesivir in severe coronavirus disease 2019: A case report. Int J Infect Dis 97:215-218. https://doi.org/10.1016/j.ijid.2020.05.050

62. Welzel T, Samba SD, Klein R et al (2021) COVID-19 in autoinflammatory diseases with immunosuppressive treatment. J Clin Med. https://doi.org/10.3390/jcm10040605

63. Ortiz-Alvarez O, Morishita K, Avery G et al (2004) Guidelines for blood test monitoring of methotrexate toxicity in juvenile idiopathic arthritis. J Rheumatol 31:2501-2506

64. Haslak F, Yildiz M, Adrovic A et al (2020) Management of childhood-onset autoinflammatory diseases during the COVID-19 pandemic. Rheumatol Int 40:1423-1431. https://doi.org/10.1007/ s00296-020-04645-x

65. Ramirez GA, Gerosa M, Beretta L et al (2020) COVID-19 in systemic lupus erythematosus: data from a survey on 417 patients. Semin Arthritis Rheum 50:1150-1157. https://doi.org/10.1016/j. semarthrit.2020.06.012

66. Hyrich KL, Machado PM (2021) Rheumatic disease and COVID19: epidemiology and outcomes. Nat Rev Rheumatol 17:71-72. https://doi.org/10.1038/s41584-020-00562-2

Publisher's Note Springer Nature remains neutral with regard to jurisdictional claims in published maps and institutional affiliations. 